\title{
9
}

\section{CREATIVITY IN THE EVERYDAY: CULTURE, SELF, AND EMOTIONS}

\author{
LOUISE SUNDARARAJAN AND JAMES R. AVERILL
}

Art is the education of nature... The human body is an instrument for the production of art in the life of the human soul.

—Alfred North Whitehead

Nothing is more everyday than emotion, and nothing seemingly less creative. Yet, creativity in the domain of emotion, both eminent and everyday, is the topic of this chapter. As in other domains of creativity, a creative response must be effective in meeting some challenge or standard of excellence. Two other criteria for creativity are novelty and authenticity. Novelty requires that the response be unique to the individual or group, and authenticity requires that the response originates in the self, as opposed to being an imitation or copy. (As here conceived, the "self" can extend beyond the boundaries of the individual person.) The exact weight given to the criteria of novelty and authenticity may vary from one person to another, from one domain of creativity to another, and, most important for our present concerns, from one culture to another.

A second major concern of this chapter is the way cultures differ in the criteria for assessing creativity. Western cultures are often characterized as individualistic, and Eastern cultures as collectivist. These cultural orientations, we suggest, reflect dimensions along which a person's intra- and interpersonal transactions may vary, namely through (a) differentiation and (b) involvement. Through literary examples-John Keats from the West 
and Ssu-k'ung T'u from the East-we illustrate how differentiation and involvement relate to novelty and authenticity.

A third area of our investigation is how cultural differences can translate into individual differences in creativity. As in other domains, people differ in their ability to be emotionally creative. We relate such differences to self-construals that reflect the collectivism-individualism cultural divide and, more specifically, to the way elements of novelty and authenticity are differentially blended in the cognitive life-space of the person.

Last, we reflect on the difference and continuity between the eminent and the everyday in emotional creativity. Needless to say, emotions expressed in literature are not the same as emotions expressed in everyday life: The former may be considered eminent and the latter everyday; moreover, the former are manifested in words and images, whereas the latter may also involve bodily reactions. However, to the extent that, at their creative best, emotions are made an embodied art (cf. the epigram by Whitehead); the ideals of eminent and everyday creativity may converge in the emotional life. This continuity between life and art is emphasized in the Chinese tradition.

\section{EMOTIONAL CREATIVITY, FROM THE EMINENT TO THE EVERYDAY}

At first blush, the juxtaposition of "emotion" with "creativity" might seem like an oxymoron. Consider, for example, the following observations by Robert Zajonc (1998), writing in the authoritative Handbook of Social Psychology:

At the basic level we share emotions with lower animals. Except for trivial features, cognitions are probably uniquely human.... There are 'cognitive virtuosos' - mathematical prodigies, mnemonists, geniusesbut there are no 'emotional prodigies.' We can speak of an 'intellectual giant' but an 'emotional giant' is an absurdity. (p. 597)

We can only guess why the idea of an "emotional giant" seemed absurd to Zajonc. Human beings are not only the most intelligent of species but also the most emotional: Simple observation indicated that humans experience a greater variety of emotions than do chimpanzees; chimpanzees, greater than dogs; dogs, greater than mice; and so on down the "great chain of being." Stated differently, emotional and intellectual capacities have evolved together. This fact alone might suggest that the idea of emotional creativity is not an absurdity. William James, for one, did not think it absurd: "When a person has an inborn genius for certain emotions, his life differs strangely from that of ordinary people" (1902/1961, p. 215).

In the passage cited earlier, Zajonc (1998) mentioned two eminent mathematicians, Gauss and Pascal, as examples of cognitive virtuosos. 
Applying James's observation to geniuses such as these, we might say that the world of mathematics also differs strangely from that of ordinary people. Yet, is it any less strange than the world of Augustine, say, or Dante, both of whom might be considered emotional geniuses? Genius in any domain is, by definition, rare and hence in some sense strange--but not thereby absurd.

If we turn from the eminent to the everyday, the idea of emotional creativity is as old as Aristotle, albeit under a different name-catharsis. We do not mean catharsis in the sense of purgation, which is only one possible translation of the original Greek. Aristotle's meaning is better captured by the notion of perfecting the emotions: By viewing drama or tragedy, the ordinary person learns to respond emotionally in new and presumably better ways (Oatley, 1999; Averill, 2001).

Also relevant to emotional creativity is the ancient Stoic distinction between first and second movements. The Stoics disagreed with Aristotle that emotions could be perfected. For the Stoics, the emotions were literally pathologies (pathe $)$, and hence were to be expurgated completely. An obvious objection to this Stoic thesis is that we often respond in immediate and adaptive ways to painful and pleasurable events. Are we to deny that such reactions are emotions? Yes, according to the Stoics. Such reactions are only "first movements," automatic responses, such as turning pale at a frightening event, that are preliminary to the real emotion, which is a "second movement" that requires an additional assessment about what to do.

Some contemporary theories make a distinction similar to that made by the Stoics, but they make the opposite identification. That is, the real emotion is identified with an immediate reaction that may last for only moments; subsequent cognitive assessments are dismissed as secondary elaborations. Which conception is correct: Are emotions limited to first movements only, or do they also include second movements? The answer is both: The concept of emotion is sufficiently broad to encompass first and second movements. If we had to choose, however, we believe the Stoics had the better argument, provided we ignore their insistence that anything done out of emotion could be better done following rational deliberation (cf. Nussbaum, 1994).

We call attention to the Stoic position because it helps to clarify the limits of emotional creativity. The person who is suddenly confronted by the proverbial bear in the woods does not have time to be creative. His emotional response, at least immediately, comprises mainly "first movements." However, most emotional episodes are not like this, and they allow ample opportunity for innovation and change during the "second movement."

Some of the best evidence for emotional creativity comes from cultural differences in emotional syndromes; for example, aggression and related emotions may be unheard of in one culture (e.g., the Utku, described by 
Briggs, 1970), but considered fundamental in another (e.g., the Yanomamö, described by Chagnon, 1992). Although such variations in emotional syndromes are well documented, the tendency has been to interpret them as a mere patina on more "basic" (biologically primitive) emotions. That tendency is itself a cultural prejudice, one deeply ingrained in Western intellectual history (Averill, 1974). We take a different view.

Given that emotions differ across cultures, the question arises: How did such variations come to be? The answer, we believe, is to be found in the emotional creativity of individuals, from the eminent to the everyday. At the level of eminent creativity, a genius with a new vision for emotions finds a niche for the new development. Augustine (1948) was such a person, a man of many and strong emotions: "Man is a great deep, Lord. You number his very hairs and they are not lost in your sight: but the hairs of his head are easier to number than his affections and the movements of his heart" (p. 14). Contrary to the Stoic notion of emotions as inherently pathological, Augustine's vision of human nature gave centrality to emotions: "In the Confessions for the first time in history is the analysis of the wellsprings of anxieties and frustrations of the modern soul" (Sheen, 1949, p. xi). Similarly, Confucius in China made refinement of emotions central to the selfcultivation of all Chinese who consider themselves "civilized" (Frijda \& Sundararajan, in press; Sundararajan, 2002a).

At an intermediate level of creativity, practices emblematic of the new emotional order are needed. Legions of innovators-artists, poets, spiritual and political leaders-produce works that provide templates for everyday living. Continuing with Augustine as an exemplar in the West, his notion of the self as having a hidden dimension that is seething with emotional energy, and privy only to God or self-introspection, has been propagated through mystics in the medieval times and Freud and other thinkers in modern times. Similarly, great poets in China, such as Tu Fu and countless others elaborated on and made popular the Confucian vision of refined emotions (Sundararajan, 1998, 2002a).

At the level of everyday creativity, ordinary people live the vision of the trendsetters, often with variations that, if proven viable, percolate upward through the society. Thus, in addition to a top-down progression, from the eminent to the everyday, emotional creativity proceeds in a bottom-up direction, from the everyday to the eminent. The latter, in fact, is undoubtedly the more common mode of progression, although it is less easy to demonstrate because of its commonness and diffuseness. We will have more to say about everyday emotional creativity in a later section. For now, suffice it to note that social evolution, like biological evolution, typically proceeds in small increments, the cumulative effect of which is only solidified and made apparent through such "emotional geniuses" as Augustine and Confucius. 
Emotional creativity is not ancient history. Carl Rogers provides a contemporary example. Born into a fundamentalist Christian family, Rogers was shy as a youth and married his childhood sweetheart--hardly the background for a "hidden genius of emotion" (Magai \& Haviland-Jones, 2002). Yet, Rogers had a vision for a particular kind of emotional attunement that is therapeutic, and subsequently found a niche for this practice in clientcentered therapy. At the next level in the top-down progression, clientcentered therapists made Rogerian theory and techniques available to a wide audience. Finally, at the level of everyday creativity, a multitude of people innovated on the vision of Rogers in encounter groups and other countercultural movements of the 1960s.

The stage is now set for exploring emotional creativity in the cultural contexts of Eastern and Western societies. (By "Eastern," we mean the East Asian societies of China, Korea, and Japan; by "Western," we mean any country within the European cultural tradition, regardless of geographical location.)

\section{CRITERIA FOR CREATIVITY IN CULTURAL CONTEXT}

How do we determine whether an emotional response is creative? There are three criteria. The first is effectiveness. For a response to be considered creative, it must be effective in meeting some challenge, for example, aesthetically in the case of art, commercially in the case of business, theoretically in the case of science, and, we suggest, interpersonally in the case of emotion. Needless to say, what counts as effective may vary from one domain to another, but also from one culture to another. Yet, regardless of domain or culture, no response will be considered creative unless it is of value.

Next to effectiveness, the most commonly mentioned criterion for creativity is novelty; that is, the creative response should be unique or different in some respect. As Arnheim (1966) has emphasized, however, novelty can be-indeed, typically has been-overemphasized. Difference for difference' sake, even when effective, may be a sign of eccentricity rather than creativity. Therefore, a third criterion must be added, namely, authenticity. Authenticity is a complex concept, but as we are using it here, it captures what Arnheim had in mind when he spoke of the "pregnant sight of reality" as a hallmark of creativity. The creative response must reflect the person's own vision of reality, whether novel or not.

Cultures differ not only in the emotions they recognize as standard, as the earlier examples of the Utku and Yanomamö illustrate, but they also differ in the extent to which they encourage or tolerate emotional creativity. This is particularly true with reference to the criteria of novelty and authenticity. In particular, Eastern societies place greater emphasis on authenticity 
than on novelty, whereas Western societies have the reverse emphasis (Averill, Chon, \& Hahn, 2001; Sundararajan, 2002a). This point becomes clear in a dimensional analysis of culture. (See chaps. $3 \& 8$, this volume, for movement toward the more Eastern configuration in spiritual "balance" or healing.)

\section{Dimensions of Culture}

Authenticity and novelty differ in directions of cognitive attentioninward toward the self versus outward toward the world, orientations that help shape the nature and content of our emotional experiences, as discussed, for example, by Marcel and colleagues (Lambie \& Marcel, 2002). To elaborate on the difference in cognitive attention between authenticity and novelty, we propose two universal dimensions along which a person's intraand interpersonal transactions may vary, namely, (a) differentiation and (b) degree of involvement. These dimensions are illustrated in Figure 9.1.

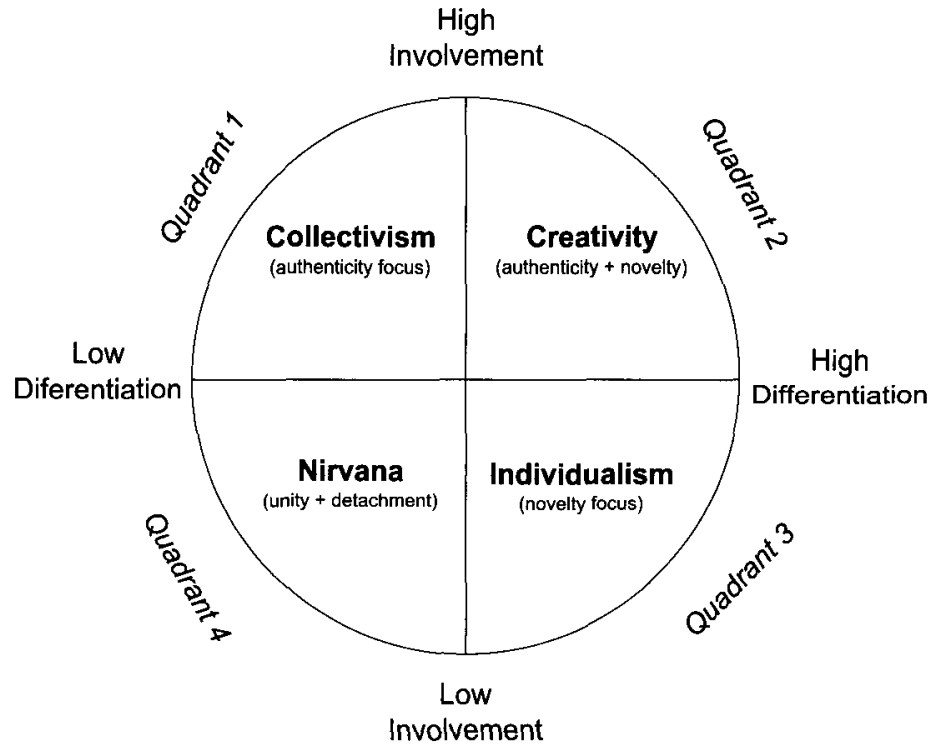

Figure 9.1. Two dimensions-differentiation and involvement-along which intrapersonal (self-to-self) and interpersonal (self-to-other) relations may vary. An authenticity focus, whether on the individual (interdependent) or cultural (collectivist) level, reflects high involvement and low differentiation (Quadrant 1), and conversely for a novelty focus (Quadrant 3). Creativity in its everyday sense (Quadrant 2) reflects a "blended space" that incorporates both the criteria of authenticity and novelty. A "blended space" of low involvement (detachment) and low differentiation (unity) can also be creative, but in a more esoteric sense, for example, as illustrated by the Buddhist concept of Nirvana (Quadrant 4). 
The meaning of these dimensions is easiest to illustrate in the context of interpersonal relationships.

Differentiation, the horizontal axis in Figure 9.1, is anchored at the high end by perceived differences and at the low end by perceived similarities. That is, highly differentiated persons perceive themselves as unique and different from others.

Involvement, the vertical axis in Figure 9.1, is anchored at the high end by a sense of solidarity or integration and at the low end by a sense of separateness. People who perceive themselves as unique (highly differentiated) may still be highly involved in the lives of others; conversely, people who perceive themselves as similar to others (low differentiation) can nevertheless be socially disengaged or uninvolved. Hence, the two axes are depicted as orthogonal in Figure 9.1.

As noted earlier, the dimensions of Differentiation and Involvement can be interpreted on the intrapersonal (subjective) as well as interpersonal levels of analysis. This is because the way we relate to ourselves is a reflection of how we relate to others, says Vygotsky (1978) and others; the other way around is also true, says the philosopher Charles Peirce (Sundararajan \& Schubert, 2005). How Differentiation and Involvement play out in the intrapersonal dimension is of particular relevance to creativity, as we shall see.

As illustrated in Figure 9.1, Authenticity (Quadrant 1) is characterized by high involvement (participation, solidarity, integration, etc.) and low differentiation (similarity, redundancy, etc.). These themes are best articulated by an inward orientation, a self-to-self relationship in which the partners of the transaction are the most similar "other." By contrast, Novelty (Quadrant 3) is characterized by low involvement (psychological distance, instrumentality, objectivity, etc.), and high differentiation (difference, uniqueness, etc.). These themes are best articulated by an outward orientation, a self-to-nonself relationship in which the partners of the transaction are dissimilar. This is the self-to-world transaction in which instrumentality and objectivity become important mental sets. Cast in the cross-cultural context, Eastern cultures show an intrapersonal orientation that privileges self-transformation and self-integration, whereas Western cultures value actions that change the world.

Creative people and societies, we chapter authors contend, inhabit the "blended space" (Turner, 1996) of Quadrant 2, which combines selective elements of novelty and authenticity (Averill \& Sundararajan, 2005). This leaves Quadrant 4, characterized by low involvement and low differentiation. This condition is undoubtedly unstable, for most people cannot remain indifferent (low involvement), especially to those they perceive as similar (low differentiation). Furthermore, they cannot remain indifferent to themselves. However, there can be a positive side to this quadrant, particularly on the intrapersonal (self-reflexive) level. We have in mind the Buddhist 
notion of Nirvana, which reduces everything to the ground state of nonbeing, and all passion to detachment.

\section{Collectivism Versus Individualism}

Eastern societies are often described as collectivist and Western societies as individualistic (Triandis, 1995). Collectivist cultures are characterized by high involvement and low differentiation. That is also the space represented by Quadrant 1 (Figure 9.1). Similarly, individualistic cultures are characterized by low involvement and high differentiation and hence occupy the space represented by Quadrant 3. With regard to the criteria for creativity, we thus propose a relation between Authenticity and Collectivism, on the one hand, and Novelty and Individualism, on the other. Since the emphasis on these criteria is relative, not exclusive, we may state the proposed relations as follows: Expressions of authenticity for people in individualistic cultures will have a novelty slant, whereas expressions of novelty in collectivist cultures will have an authenticity slant.

To demonstrate the proposed relations, we draw on two sources. First, we contrast the works of two poets, John Keats (English, 1795-1821) and Ssu-k'ung T'u (pronounced ss-coon-too; Chinese, 837-908), to illustrate cultural differences in conceptions of creativity and the self; second, we present empirical data to show how self-reports of authenticity and novelty correlate with measures of collectivism and individualism.

\section{SIMULATIONS OF EMOTIONAL CREATIVITY IN POETRY}

Wordsworth (1805/1952) famously described poetry as "the spontaneous overflow of powerful feelings: it takes its origin from emotion recollected in tranquility ... the tranquility gradually disappears, and an emotion, kindred to that which was before the subject of contemplation, is gradually produced, and does itself actually exist in the mind" (p. 84). Couched in terms of modern computer science, Oatley (1999) has made a similar point, namely, that works of literature are ways of simulating emotions. Just as computer simulations give us a useful model of the weather, simulations of emotions through literature provide models of creativity.

\section{Models of Creativity, East and West}

For the Western notion of creativity, we examine John Keats's poem "To Autumn," in which the potency of nature becomes the metaphor for the power to create. The following lines are particularly pertinent: 
Conspiring with him [the sun] how to load and bless

With fruit the vines that round the thatch-eves run;

To bend with apples the moss'd cottage-trees,

And fill all fruit with ripeness to the core;

To swell the gourd, and plump the hazel shells,

With a sweet kernel ... (cited in Fish, 1980, p. 263)

Consistent with our proposed novelty-focus cultures, Keats's "To Autumn" is a model of creativity with high differentiation and low involvement. Highly differentiated is the creator's role: It is on a different order of being from the created. Corresponding to the dichotomy between the creator and the created are binary oppositions between subject and object; action and passion. The creator-autumn-is the one who acts; the created-fruits, nuts, and vegetation-is the object being acted on. Coupled with this discontinuity in being is instrumental rationality that guides action. Donald Freeman (1978) in his nuanced analysis of this poem noted a plethora of verbs-loads, blesses, bends, fills, swells, and plumps-and instrumental phrases: "with fruit," with apples," with ripeness," and "with a sweet kernel." This observation led Fish (1980) to the conclusion that "The overriding agency of Autumn, by making everything her object, makes everything her instrument, even the sun" (p. 264).

In sharp contrast is the Chinese notion of creativity. Not having a creator myth, the Chinese notion of nature becomes necessarily selfreferential: Nature is self-generating and self-renewing. In fact, the Chinese term for nature is ziran which means literally "self-so-ing" (Hall \& Ames, 1995, p. 231). As can be expected, the Chinese notion of creativity is high in involvement and low in differentiation. A case in point is Ssu-k'ung T'u's poem on chaos-the primordial principle of creativity-entitled "Hsiung-hun":

Great power manifested without,

The genuine form is inwardly full;

Return to the void, enter the All

Gathering vigor it becomes potent.

Containing a myriad phenomena,

It extends across the great void,

Pale and billowing rain clouds,

Long winds in the empty vastness.

Leap beyond images and appearances

To reach the circle's center-

Hold it without coercion,

It will come without end. (Adapted from Yu, 1978, p. 93)

This poem, like many others by Ssu-k'ung T'u, shares with computer simulations a two-tiered structure of simulation per se, on the one hand, and instructions about how to conduct the simulation on the other (Oatley, 
1999). Lines 1 through 9 are mental simulations of the Tao as primordial Chaos; the coda (Lines 10-12) gives instructions as to how best to appropriate this primordial source of energy and creativity. The title "HsiungHun" literally means "potent, undifferentiated" (Owen, 1992, p. 303). The "undifferentiated" (hun) is "the primordial state of chaos," in which "all emergent shapes are constantly changing and blurring into all others" (p. 305). Ssu-k'ung T'u's imagery for this potent and primordial state is the flowing clouds: "The clouds are an appropriate sensuous form for hun [undifferentiated], while the steady gale that drives them will be associated with hsiung [potent]" (Owen, 1992, p. 305). This poem shares with Keats's "To Autumn" an emphasis on the energy and dynamism of the creative process.

In her exquisite analysis of this poem on chaos, Pauline Yu noted that "The interaction between inner and outer in lines 1-2 and 9-10, along with the active verbs fan [return], $j u$ [enter], heng [extend], chüeh [(cutting) across], yu [flowing/billowing], ch'ao [leap beyond], all create a sense of movement" (1978, p. 94). Likewise, Owen (1992) claims that this poem celebrated "ceaseless activity" flowing from "pure potentiality" (p. 305). He explains that since "'potent, undifferentiated' (in Ssu-k'ung T'u's version) is not a truly determinate quality in its own right, but rather a capacity to produce all determinate qualities, it can be manifest only in the impression of energy, in an ability constantly to produce new forms and transformations of old ones" (p. 306). Yet, the activities of the Tao in its primordial state of chaos differ drastically from those of autumn as envisioned by Keats.

Whereas the transitive verbs of Keats's autumn accentuate mastery over the world, actions of the primordial chaos are mostly couched in terms of intransitive verbs such as returning, billowing, leaping-activities which render the doer "at once the desert, the traveler, and the camel," to borrow a felicitous phrase from Flaubert (cited in Blanchot, 1981, p. 127). Indeed, forceful action is explicitly forbidden in the coda of this poem: "Hold it [the creative force] without coercion,/It will come without end." What creativity of the Tao exemplifies is not mastery without, but integration within. The Chinese notions of authenticity and self-integration are frequently articulated by the binary opposition of inner and outer (Sundararajan, 2002a). The inner and outer dichotomy is underlined at the outset of this poem on chaos: "Great power manifested without,/The genuine form is inwardly full" (Lines $1-2$ ). The exact relationship between the inner and the outer is open to multiple interpretations, of which Owen (1992) sampled a few from various commentaries: "the outward is an extension of the inner ... or the outward transforms while the inner stays the same, or the outward must 'wither away' so that the inward can be nurtured" (p. 305). Whatever the case may be, the emphasis is on the integration of the inner and the 
outer, as the next line has it: "Return to the void, enter the All." The term return marks the reflexive movement of self-integration, thereby the creative force that engages itself in the world of forms and actions is able to replenish itself periodically by returning to the source, the void, or what is later referred to as the circle's center (Line 10) - "the empty space around which a wheel turns" - where the "still unrealized power for transformation" resides (Owen, 1992, p. 304).

Thus far, we have used poetry to simulate models of creativity in general. We turn now to creativity as it relates more specifically to emotional experiences. For consistency, we draw on the life and work of the same two poets, John Keats and Ssu-k'ung T'u.

\section{John Keats on Negative Capability}

The contours of a person's self are outlined in emotion: Our hopes and fears, joys and sorrows, loves and hates-these and the myriad of other emotions experienced in everyday life are markers of who we are. Any fundamental change in emotion thus involves a change in the self, and vice versa.

An innovative notion of the self is expressed by Keats in his theory of "negative capability," which consists of a twofold capacity: (a) "to efface the self through sympathetic identification with others," and (b) to remain in "uncertainties, Mysteries, doubts without any irritable reaching after fact and reason," as Keats put it (Kucich, 2001, p. 193). The submergence of the self in the nonself is a salient theme in the works of Keats. Barnard points out that behind Keats's pursuit of sensations lies a deeper yearning, namely for "Being [to be] taken up into sensation, into something deeply other to the self" (1990, p. 63). Mellor notes that Keats's "camelion [sic]" self is a self that is "permeable, continually overflowing its boundaries, melting into another, and being filled by another" (2001, p. 216). Clubbe and Lovell, Jr. make the similar observation: "Such a poet quite literally lives not in the limited self but in other selves" (1990, p. 135). Commenting on the confession of Keats that "In a room with People ... then not myself goes home to myself: but the identity of every one in the room begins to press upon me that, I am in a very little time an[ni]hilated" (cited by Clubbe \& Lovell, Jr., 1990, p. 135), the authors conclude that "This is the expansionist urge to move outside the self, to unite with that which is the not-self" (1990, p. 135).

The theme of self-effacement through identification with the larger whole is an expression of self-transcendence. Counterintuitive as this may sound, self-transcendence is an expression of authenticity for the following reasons: (a) the "selfless" poet does in fact have a self, albeit an expanded, 
all-inclusive one; (b) self-transcendence capitalizes on one important theme of authenticity-low differentiation or high similarity (the self's identification or merge with the nonself). However, Keats's version of authenticity may be considered authenticity with a novelty slant. The novelty theme is salient in Keats's celebration of multiplicity and experience: "If a Sparrow come before my Window I take part in its existince [sic] and peck about the Gravel," wrote Keats (cited in Clubbe \& Lovell, Jr., 1990, p. 135). Clubbe and Lovell, Jr. point out that the chameleon-poet of "no identity" is "a being of immense variety and breadth, delighting in every level of existence, unconfined by puritanical or rationalistic restraints" (1990, p. 134). At a deeper level, Keats's ever so changeable chameleon self that capitalizes on multiplicity rather than identity, is part and parcel of his agenda to amass experiences: "O for a Life of Sensations rather than of Thoughts!" as he puts it (cited in Stillinger, 2001, p. 257). Faint echoes of this theme can be found in the modern West, where the "passionate quest for experience" (Florida, 2002, p. 166) seems to be characteristic of the successful business person as well as the successful poet. In the eloquent words of Florida, the aspiration is to "live the life'-a creative life packed full of intense, high-quality, multidimensional experiences" (p. 166).

Florida's (2002) investigation indicates that the novelty orientation goes hand-in-hand with affluent societies. What about societies with limited resources? How do members of such a community manage to maximize their experiences? For the answer to this question, we turn to Ssu-k'ung T'u.

\section{Ssu-k'ung T'u on the Art of Savoring}

If Keats is like a kid who manages to taste as many lollipops as possible by vicariously filling in the shoes of other lollipop-possessing kids, we may think of Ssu-k'ung T'u as a kid who possesses only one lollipop, but manages to savor that one in all its nuances. Savoring is a strategy that capitalizes on redundancy rather than difference-to multiply one's experience is to double back, to reexperience an experience. It is novelty with an authenticity slant. Ssu-k'ung T'u's theory of savoring is cast in the framework of "flavor beyond flavor," the gist of which can be found in the following statements he made in a letter to a certain Mr. Li:

[I]n my opinion we can adequately speak of poetry only in terms of making distinctions in flavors. In everything that suits the palate in the region south of Chiang-ling, if it is a pickled dish, then it is indeed sour-but it is nothing more than sour. If it is a briny dish, then it is quite salty-but nothing more than salty. The reason people from the north, when eating such food, simply satisfy their hunger and then stop eating is that they recognize it somehow falls short of perfect excellence 
and lacks something beyond the distinction between "the merely sour" and "the merely salty." (Owen, 1992, p. 351)

The ideal poet, according to Ssu-k'ung T'u, is able to make subtle discriminations beyond the emotional equivalent of saltiness or sourness. Owen explains: "The opposition is between gross categories that have names, and fine judgments for which there are no names. Furthermore, those finer gradations are learned by experience: One who knows only the gross categories can apprehend only the gross categories; to be able to recognize the finer distinctions requires the education of a sensibility" (1992, p. 352). "Exactly this kind of sensitivity lies at the root of creativity" (p. 90) says Gelernter (1994) in reference to subtle discrimination of emotional nuances. The novelty dimension of savoring has to do with what Gelernter (1994) refers to as emotional acuity, which is defined in terms of the following sensibilities: (a) that you are able to register subtle or nuanced emotionsto experience subtle emotional reactions-when less acute people would have no emotional reaction at all; and (b) that you are able to distinguish many elements in a subtle emotional palette, when a less acute person would distinguish the emotional equivalent of red, green, blue.

The second component of savoring is to reexperience an experiencenot vicariously someone else's, but one's own. Self-reflexivity is definitive of savoring to the extent that one cannot savor the taste or experience of someone else. This self-reflexive dimension of savoring entails what is known as second-order awareness (Sundararajan, 2001, 2002b, 2004a). In contrast to the first-order awareness of tasting the flavors in food, savoring capitalizes on the second-order awareness of knowing that one knows the flavors so as to manipulate the experience by prolonging it, making fine discriminations of it, and so forth. In the final analysis, savoring is a redundancy game. It is not fortuitous that Ssu-k'ung T'u used the term flavor twice in his "flavor beyond flavor." The redundancy reiterates the idea that savoring is a secondorder awareness of the first-order taste-the "merely" sour or salty, or perhaps the equivalent of "basic" emotions in contemporary psychology. Likewise in common parlance, savoring is called hui-wei (resavoring), where the prefix hui means "again" or "twice," as in "twice-cooked pork," hui-guorou.

The Chinese notion of savoring is broader in scope than the contemporary Western formulation of the same (Bryant \& Veroff, 2007), which is confined to that of positive experiences only. The Chinese notion of savoring, by contrast, refers to the ability to appreciate and derive aesthetic pleasure from negative events as well as positive ones (Sundararajan, 2004a, in press), and as such is characteristic of emotionally creative individuals (for clinical application of savoring, see Sundararajan, 2001, in press). Furthermore, this self-reflexive dimension is missing in the contemporary 
formulation of savoring (Bryant, 1989), which centers on the ability to amplify or prolong enjoyment of positive events without taking into consideration the role of second-order awareness. The Chinese notion of savoring, by contrast, is broader in scope. Whereas in Bryant's formulation savoring is confined to that of positive experiences, the Chinese notion of savoring refers to the ability to appreciate and derive aesthetic pleasure from negative events as well as positive ones (Sundararajan, 2004a, in press), and as such is characteristic of emotionally creative individuals (for clinical application of savoring, see Sundararajan, 2001). Whereas the Western notion of savoring entails basically the sense of relishing an experience in the here and now, the Chinese notion of savoring focuses not on the stimulus in situ so much as on its poststimulus persistence. Thus Owen states that "Chinese theorists tended not to speak of disjunctive acts of reflection on the 'meaning' of a text, but rather of the 'continuation' of the text in the mind after reading is over, a time in which the significance of the text gradually unfolds" (1992, pp. 593-594). The same is true with "hui-wei" (retasting), which refers to "a recollection in the mind of a previously encountered flavor" (Eoyang, 1993, p. 230). In the final analysis, self-referentiality is an indispensable dimension to savoring-what is experienced in savoring is not simply the stimuli, but the self as well. Savoring is an affirmation of the self as point of reference of all its experiences-an integrated self with its taste, values, and memories as the sole measure of what is worth savoring.

\section{EMOTIONAL CREATIVITY IN THE EVERYDAY}

The use of eminent poets, such as Keats and Ssu-k'ung T'u, to model everyday emotional creativity involves a contradiction: The eminent is not the everyday. In this section, therefore, the chapter authors extend our analysis to include individual differences in the ability to be emotionally creative, and how such differences relate to independent and interdependent self-construals, reflective of individualist and collectivist cultural orientations, respectively. As before, our major focus is on novelty and authenticity as criteria for creativity.

\section{Assessing Everyday Emotional Creativity}

Creativity occurs in stages, from initial preparation to verification and diffusion of the final product. The criteria for creativity mentioned earlier (novelty, authenticity, effectiveness) pertain to the stage of verification; that is, they represent standards for evaluating a response as creative. The best predictor of future behavior is past performance. Therefore, the application of these criteria to past and current emotions provides one way to assess 
TABLE 9.1

Sample Items From the Emotional Creativity Inventory

\begin{tabular}{|c|c|}
\hline Category & Item \\
\hline $\begin{array}{l}\text { Preparation } \\
\text { ( } 7 \text { items total) }\end{array}$ & $\begin{array}{l}\text { I think about and try to understand my emotional } \\
\text { reactions. } \\
\text { I pay attention to other peoples' emotions so that I } \\
\text { can better understand my own. }\end{array}$ \\
\hline $\begin{array}{l}\text { Novelty } \\
\text { (14 items total) }\end{array}$ & $\begin{array}{l}\text { My emotional reactions are different and unique. } \\
\text { I have felt combinations of emotions that other people } \\
\text { probably have never experienced. } \\
\text { I sometimes experience feelings and emotions that } \\
\text { cannot be easily described in ordinary language. }\end{array}$ \\
\hline $\begin{array}{l}\text { Effectiveness/Authenticity } \\
\text { ( } 9 \text { items total) }\end{array}$ & $\begin{array}{l}\text { My emotions help me achieve my goals in life. } \\
\text { I try to be honest about my emotional reactions, even } \\
\text { when it causes me problems. } \\
\text { My outward emotional reactions accurately reflect my } \\
\text { inner feelings. }\end{array}$ \\
\hline
\end{tabular}

individual differences in emotional creativity. The initial stage of the creative process-preparation-provides another way. Some people consider emotions important to their lives; thus, they think about and try to understand their emotions, and they are sensitive to the emotions of others. We may assume that, on average, such people are better prepared emotionally than are their more indifferent (but not necessarily less reactive) counterparts.

On the basis of this rationale, a 30-item Emotional Creativity Inventory (ECI) has been constructed (Averill, 1999). Seven of the items refer to emotional preparation, 14 to the novelty of emotional experiences, 5 to effectiveness, and 4 to authenticity. Sample items from each category are presented in Table 9.1.

Although basically unidimensional, factor analyses suggest that the ECI can be broken down into three more homogeneous facets. The first facet represents emotional preparedness; the second facet, novelty; and the third facet a combination of effectiveness and authenticity. Using self-report measures, it has proved difficult to distinguish the perceived effectiveness of a response from its authenticity; people tend to judge their own emotions effective to the extent that they are authentic, and vice versa.

People who score high on the ECI are rated by their peers as emotionally more creative than are low scorers, and they are better able to express unusual emotions symbolically in stories and pictures (Averill, 1999; Averill \& Thomas-Knowles, 1991; Gutbezhal \& Averill, 1996). People who score high on the ECI are also better able than low scorers to benefit from solitude, a condition that traditionally has been associated with creative pursuits in a variety of fields (Long, Seburn, Averill, \& More, 2003). 
In terms of the "Big Five" personality factors (Costa \& McCrae, 1985), the ECI is most closely related to Openness and Experience, but it is independent of Extraversion and Neuroticism, two traits closely related to positive and negative emotionality, respectively. The ECI is also modestly correlated with agreeableness (another of the Big Five), self-esteem, and an antiauthoritarian attitude (Averill, 1999). In short, the ECI seems to have reasonable construct validity, using both performance and self-report measures.

With regard to discriminant validity, total scores on the ECI are unrelated to general intelligence, as measured by SAT scores (Averill, 1999), or to emotional intelligence, as measured by the Mayer-Salovey-Caruso Emotional Intelligence Test (MSCEIT), a performance-based measure of emotional abilities (Ivcevic, Brackett, \& Mayer, 2007).

\section{Novelty and Authenticity in Relation to Collectivism and Individualism}

As discussed earlier with reference to Figure 9.1, collectivist cultures are characterized by high involvement and low differentiation (Quadrant 1), and hence occupy the same space as Authenticity; by contrast, individualistic cultures are characterized by low involvement and high differentiation (Quadrant 3), and hence occupy the same space as Novelty. It is thus reasonable to infer that collectivist cultures will have an authenticity focus and individualistic cultures a novelty focus (Averill et al., 2001). Nicole Giglio (2002) explored this possibility as part of her senior honors thesis.

Not all individualist and collectivist societies are organized in the same manner; for instance, some are hierarchically organized whereas others have an egalitarian structure. This has led to a fourfold distinction between vertical and horizontal varieties of individualism and collectivism, with self-report scales to match (Singeles, Triandis, Bhawuk, \& Gelfand, 1995). In a sample of 199 ( 35 male, 162 female, 2 unspecified) American university students, Giglio (2002) found no relation between total scores on the ECI and either of the vertical individualism or vertical collectivism scales $(r=.11$, and -.03 , respectively). This is not surprising since, as noted earlier, persons who score high on ECI tend to be nonauthoritarian. However, the ECI was highly correlated with horizontal individualism $(r[197]=.47, p<.001)$, and somewhat less so with horizontal collectivism $(r[197]=.22, p<.01)$.

The main concern of Giglio's thesis was not with emotional creativity as a whole; rather, it was with the relation between novelty and authenticity, on the one hand, and individualism and collectivism, on the other. Two scales were formed for this purpose: One scale consisted of the original 14 novelty items from the ECI (coefficient alpha $=.84$ ); the other consisted of the four authenticity items, to which 10 more similar items were added 
TABLE 9.2

Correlations Between Self-Reports of the Authenticity and Novelty of

One's Emotional Responses and the Cultural Dimensions of Horizontal Collectivism and Individualism

\begin{tabular}{lcc}
\hline & \multicolumn{2}{c}{ Cultural dimensions } \\
\cline { 2 - 3 } Creativity dimensions & Collectivism & Individualism \\
\hline Authenticity & $.28_{\mathrm{a}}$ & $.26_{\mathrm{a}}$ \\
Novelty & $.05_{\mathrm{b}}$ & $.36_{\mathrm{a}}$ \\
\hline
\end{tabular}

Note. Values having the same subscript ( $a$ or $b$ ) are not significantly different from one another.

(coefficient alpha for the 14 items $=.78$ ). The correlation between the two scales was nonsignificant $(r[197]=.11)$. This last result is consistent with the theoretical analysis presented earlier, in which creativity represents a blended space of both novelty and authenticity, assuming equal effectiveness (see Figure 9.1).

Horizontal Collectivism and Horizontal Individualism were assessed by scales developed by Singelis et al. (1995). Table 9.2 presents the correlations between the four scales: Novelty, Authenticity, Horizontal Collectivism, and Horizontal Individualism.

The relations are in the predicted direction. That is, authenticity, but not novelty, was correlated with collectivism; the difference between these two correlations (.28 vs. .05 , respectively) was statistically significant $(t[196]=2.39, p<.05)$. Also as predicted, novelty was more highly correlated with individualism (.36) than was authenticity (.26); in this case, however, the difference did not reach statistical significance.

The correlation between authenticity and individualism (.26) deserves brief comment, for it is larger than might be expected on theoretical grounds. One possible explanation is the fact that in individualistic (e.g., Western) cultures, in which the self is often distinguished from others, the criteria of novelty and authenticity collapse into a single dimension; that is, the person is authentic by being different. Indeed, there is in contemporary Western societies what has sometimes been called "a cult of authenticity"- but it is an authenticity that is almost indistinguishable from novelty. That is, a person is considered authentic to the extent that he or she is different from others, unique in style or appearance, answering only to self-interests. This kind of authenticity is different from that found in more collectivist (e.g., Eastern) societies, where the self is not so differentiated from others, and in which a person's own interests are consistent with group norms (involvement).

In short, authenticity does not mean the same when embedded in different cultural contexts, a fact that was also found in this chapter's earlier 
comparison of the "negative capability" of John Keats and the "savoring" of Ssu-k'ung T'u. Furthermore, as Ssu-k'ung T'u's poetics suggests, even in Collectivistic societies, it is the intrapersonal version of authenticity (selfreflexivity, self-integration, etc.) rather than the interpersonal version of the same (group affiliation, sociality) that plays an important role in creativity. When measuring authenticity in future studies, it would be helpful to tease apart empirically these two variants of authenticity by devising items in which a self-referential (self-to-self) orientation (e.g., "I feel good when I can express my emotions fully and adequately in verbal communications") is pitted against a social (self-to-other) orientation (e.g., "I feel good when I cooperate with my coworkers").

\section{DISCUSSION}

This chapter has focused on emotions as potential objects of creativity. The analysis, however, has implications beyond the emotions-to art and literature, especially poetry, on the one hand, and to the self, culture, and human nature, on the other. These implications deserve brief additional discussion. The chapter began with the gap sometimes observed between the eminent creativity of great poets, as exemplified, for example, by Keats and Ssu-k'ung T'u, and the everyday experience of emotion. The authors then considered the bidirectional relation between emotion and culture, and how each helps to fashion the other. Finally, we concluded the chapter with a few observations on the triadic relation between emotions, culture, and human nature.

\section{The Gap Between Eminent and Everyday Creativity, in Poetry and in Life}

Let us return for a moment to Wordsworth's (1805/1952) description of poetry as "the spontaneous overflow of powerful feelings ... recollected in tranquility." The phrase highlights the close relation between poetry and everyday emotional experiences, but it is also misleading. In poetry, emotions are not so much recollected as imagined. It is one thing for a poet to recollect or imagine an emotion in novel and particularly effective ways; it is another thing to enact that emotion in everyday life. The person who is good at one need not be good at the other. To a certain extent, the two may even be incompatible. Poetry is primarily cognitive; emotions are "embodied" and cannot be abstracted, without distortion, from the whole person and from the rest of life (Sundararajan, 2005).

Domains of eminent creativity, such as arts and sciences, may be compared to clearings in a forest. To the extent that the clearings are well 
maintained, there will be discontinuity or gaps between the eminent product and the rest of life, just as the clearing is distinct from the rest of the woods (Sundararajan, 2002c). The arena for everyday creativity, in contrast, is the woods, or life itself. To the extent that life approximates the dense woods with an overgrowth of conventions, creativity in the everyday may be more difficult than eminent creativity.

It is not surprising, then, that creative poets in both the East and the West have not always fared well in real life. One who dances well in the clearing may stumble in the woods. The area of creativity needs to be expanded to encompass life itself-the everyday. This is the claim of the Chinese traditions, from Confucianism to Taoism and Zen. Literature and the arts may be viewed, as in Confucian poetics, as opportunities for one to rehearse more refined versions of emotions (Frijda \& Sundararajan, in press) to make it in the "real" world (Sundararajan, 2002a). The gap between art and life is further narrowed in traditional China as the Confucian gentlemen attempted to shape their lives according to what they modeled in poetry (Sundararajan, 2002a).

These considerations raise a further issue, namely, the relation between emotions, creativity, and culture.

\section{Emotions and Creativity in Cultural Perspective}

The claim of Zajonc (1998) that there are no "emotional giants" is understandable if by "giant" he means conspicuousness. Emotional geniuses are not as conspicuous as their cognitive counterparts. Emotion is diffused in life like salt in water-too much conspicuousness may be even pathological. There are, however, cultural differences concerning this matter: Emotional geniuses in the West, Byron being a classic example, are much more conspicuous in their emotional presentations than are most traditional Chinese poets, whose emotional lives may approximate the proverbial miso soup, the excellence of which is judged by the extent to which it loses its bean pasty taste in the mellow blend (Sundararajan, 2004b). Thus, emotional creativity is much more embedded in culture than cognitive creativity: It makes little sense to consider the formula of Einstein as being particularly "Jewish," but it is meaningful to refer to the poetry of Tu Fu as being characteristically Chinese. For a closer examination of the culture and emotion interface, the interested reader may consult a cross-cultural study of theories of emotion (Averill \& Sundararajan, 2006).

The everydayness of emotion may seem nondescript and commonplace enough to warrant the claim of universality espoused by many psychologists. On closer examination, however, life in the everyday reminds one of the proverbial island that rests on an infinite regress of ontological and epistemological turtles, which may differ from culture to culture. To illustrate this 
point, we have shown in this chapter how commonplace notions such as creativity imply different assumptions about the self and agency across cultures. We have also shown how the yardstick of judging a work to be creative differs across cultures, with the West privileging novelty and the East authenticity. Furthermore, our dimensional analysis suggests that cultural and individual differences in emotional creativity are both variations along certain universal dimensions.

This translation from cultural to individual differences is supported by empirical studies. The first line of evidence comes from cognitive psychology (Lambie \& Marcel, 2002) which has delineated a difference in cognition attention-self-to-self versus self-to-world-that shapes the content and modality of emotions. The divide of internal versus external focus has also been found to have a neurological basis (Lane et al., 1997; Gusnard et al., 2001). The possibility of a direct translation from cultural to individual differences is further supported by experimental studies that replicate the hypothetical individualistic versus collectivistic differences in the lab (Gardner, Gabriel, \& Lee, 1999). The application of ECI to differences in selfconstruals, independent versus interdependent, adds convergent evidence.

The pervasive influence of culture, however, does not necessarily spell social and historical determinism. Our model of creativity as inhabiting a blended space implies that creativity necessarily goes beyond, although not without due influence by, cultural orientations such as a novelty or authenticity focus. In the final analysis, the relationship between culture and creativity is dialectic. On the one hand, culture serves as the meme pool for creativity; on the other hand, the creative individual often breaks free of local cultures. To the extent that culture serves as meme pool for emotional creativity, the technique of method acting, where aspiring actors practice experiencing as well as expressing emotions, is pertinent. To a certain extent, we are all method actors. Our training is not formal, of course, but as children and later as adults, we learn from parents, teachers, peers, and even gossips (Rimé et al., 1998) how to be emotional in accordance to the beliefs and rules of society. Popular culture (e.g., as manifested in stories and songs) is also an important means of emotional training. To be creative, however, one needs to go beyond the popular and the stereotypical (for a Chinese perspective, see Sundararajan, 2004a).

A Chinese proverb says: "In addition to burying himself in volumes of books, a consummate scholar frees himself by traveling great distances and meeting various people" (cited in Smith \& Smith, 2005, p. 9). This recommendation has been taken seriously by all writers and artists in the Chinese tradition, and apparently even today (see Smith \& Smith, 2005), for a good reason. The Chinese proverb names two ways to break free of the local meme pool —extensive reading and traveling. The creative individual is 
like a whale that needs to swim in the ocean, not the local pond, of memes. The Chinese philosopher Chuang Tzu told the following parable:

In Sung there was a man who was skilled at making a salve to prevent chapped hands, and generation after generation his family made a living by bleaching silk in water. A traveler heard about the salve and offered to buy the prescription for a hundred measures of gold. The man called everyone to a family council. "For generations we've been bleaching silk and we've never made more than a few measures of gold," he said. "Now, if we sell our secret, we can make a hundred measures in one morning. Let's let him have it!" The traveler got the salve and introduced it to the king of $\mathrm{Wu}$, who was having trouble with the state of Yüeh. The king put the man in charge of his troops, and that winter they fought a naval battle with the men of Yüeh and gave them a bad beating. [Because the salve, by preventing the solders' hands from chapping, made it easier for them to handle their weapons.] A portion of the conquered territory was awarded to the man as a fief. The salve had the power to prevent chapped hands in either case; but one man used it to get a fief, while the other one never got beyond silk bleaching-because they used it in different ways. (Watson, 1964, pp. 28-29, italics added)

Although this story captures nicely the economic principle of creativity referred to by Sternberg as "buy low sell high" (Sternberg \& Lubart, 1991), it also brings to light another important factor, namely that one who is an outsider to the local group stands a better chance of making creative use of its meme pool. Yet a total stranger would not do. The best position to be in, as predicted by our model of creativity as inhabiting the blended space of novelty-difference and authenticity-solidarity, would be as an outsider with understanding. Thus reading (to increase one's knowledge base and understanding) and traveling have to go hand-in-hand for the aspiring poet and artist, according to traditional Chinese poetics. We hope this chapter on emotional creativity across cultures serves a similar purpose for those who consider themselves travelers in the global village of the 21 st century.

\section{CONCLUDING OBSERVATIONS}

The intimate relation between emotions and culture is bidirectional: Culture helps determine emotions, as discussed earlier, and in turn, emotions help define a culture. For example, a person, an anthropologist, say, does not participate fully as a member of another culture until he or she is able to participate in its emotional life, no matter how well he or she understands 
the culture on an intellectual level. Yet that is not all: Even more than culture, emotions help define human nature. We are not referring here to emotions as biological givens; on the contrary, we assume that all but the simplest emotions (e.g., sudden fright) are social constructions. If that were not the case, emotional creativity would have limited applicability. Throughout history, people have tended to assume that what is fundamental to their own culture (emotions being a prime example), is fundamental to humans everywhere. One manifestation of this assumption has been the unfortunate treatment of people from other cultures as somehow less than human.

Even scholars who unequivocally reject ethnocentrism may adhere uncritically to emotional fundamentalism. We started this chapter with a quote from Zajonc (1998) to the effect that the idea of an emotional genius is absurd. One reason for this seeming absurdity is the notion that emotions are fundamental to human nature: Change the emotions, and you change human nature. That conclusion, we agree is a reductio ad absurdum. The solution, however, lies not in denying the possibility of emotional creativity; rather, the solution is to recognize that the emotions are as much products of our cultural as our biological heritage. What is needed is not a change in human nature, but a change in our view of that nature, as the subtitle of this volume suggests.

\section{REFERENCES}

Arnheim, R. (1966). Toward a psychology of art. Berkeley: University of California Press.

Augustine. (1948). Confessions (J. G. Pilkington, Trans.). In J. W. Oates (Ed.), Basic writings of Saint Augustine (Vol. 1). New York: Random House.

Averill, J. R. (1974). An analysis of psychophysiological symbolism and its influence on theories of emotion. Journal for the Theory of Social Behavior, 4, 147-190.

Averill, J. R. (1999). Individual differences in emotional creativity: Structure and correlates. Journal of Personality, 67, 331-371.

Averill, J. R. (2001). The rhetoric of emotion, with a note on what makes great literature great. Empirical Studies of the Arts, 19, 5-26.

Averill, J. R. (2005). Emotions as mediators and as products of creative activity. In J. C. Kaufman \& J. Baer (Eds.), Creativity across domains: Faces of the muse (pp. 225-243). Mahwah, NJ: Erlbaum.

Averill, J. R., Chon, K. K., \& Hahn, D. W. (2001). Emotions and creativity, East and West. Asian Joumal of Social Psychology, 4, 165-183.

Averill, J. R., \& Nunley, E. P. (1992). Voyages of the heart: Living an emotionally creative life. New York: The Free Press. 
Averill, J. R., \& Sundararajan, L. (2005). Hope as rhetoric: Cultural narratives of wishing and coping. In J. Eliott (Ed.), Interdisciplinary perspectives on hope (pp. 133-165). New York: Nova Science.

Áverill, J. R., \& Sundararajan, L. (2006). Passion and Qing: Intellectual Histories of Emotion, West and East. In K. Pawlik \& G. d'Ydewalle (Eds.), Psychological concepts: An international historical perspective (pp. 101-139). Hove, England: Psychology Press.

Averill, J. R., \& Thomas-Knowles, C. (1991). Emotional creativity. In K. T. Strongman (Ed.), International review of studies on emotion (Vol. 1, pp. 269-299). London: Wiley.

Barnard, J. (1990). Endymion: "Pretty Paganism" and "Purgatory Blind." In H. de Almeida (Ed.), Critical essays on John Keats (pp. 47-67). Boston: G. K. Hall.

Blanchot, M. (1981). The gaze of Orpheus and other literary essays (L. Davis, Trans.). Barryton, NY: Station Hill.

Briggs, J. L. (1970). Never in anger: Portrait of an Eskimo family. Cambridge, MA: Harvard University Press.

Bryant, F. B. (1989). A four-factor model of perceived control: Avoiding, coping, obtaining, and savoring. Journal of Personality, 57, 773-797.

Bryant, F. B., \& Veroff, J. (2007). Saworing: A new model of positive experience. Mahwah, NJ: Erlbaum.

Chagnon, N. A. (1992). Yanomamö: The last days of Eden. New York, NY: Harcourt Brace Jovanovich.

Clubbe, J., \& Lovell, Jr., E. J. (1990). Keats the humanist. In H. de Almeida (Ed.), Critical essays on John Keats (pp. 129-142). Boston: G. K. Hall.

Costa, P. T., Jr., \& McCrae, R. R. (1985). The NEO Personality Inventory manual. Odessa, FL: Psychological Assessment Resources.

Eoyang, E. C. (1993). The transparent eye. Honolulu: University of Hawaii.

Fish, S. (1980). Is there a text in this class? Cambridge, MA: Harvard University Press.

Florida, R. (2002). The rise of the creative class. New York: Basic Books.

Freeman, D. (1978). Keats's "To Autumn": Poetry as process and pattern. Language and Style, 11, 3-17.

Frijda, N. H., \& Sundararajan, L. (in press). Emotion refinement: A theory inspired by Chinese poetics. Perspectives on Psychological Science.

Gardner, W. L., Gabriel, S., \& Lee, A. Y. (1999). "I" value freedom, but "we" value relationships: Self-construal priming mirrors cultural differences in judgment. Psychological Science, 10, 321-326.

Gelernter, D. (1994). The muse in the machine. New York: Macmillan.

Giglio, N. J. (2002). Difference in evaluating creativity based on the culture, social orientation, and political beliefs of the evaluator, and the relationship between traumatic experiences and artistic creative behavior. Unpublished senior honors thesis, University of Massachuserts, Amherst. 
Gusnard, D. A., Akbudak, E., Shulman, G. L., \& Raichle, M. E. (2001). Medial prefrontal cortex and self-referential mental activity: Relation to a default mode of brain function. Proceedings of the National Academy of Sciences, 98, $4259-4264$.

Gutbezahl, J., \& Averill, J. R. (1996). Individual differences in emotional creativity as manifested in words and pictures. Creativity Research Journal, 9, 327-337.

Hall, D. L., \& Ames, R. T. (1995). Anticipating China: Thinking through the narratives of Chinese and Western culture. Albany: State University of New York Press.

Ivcevic, Z., Brackett, M. A., \& Mayer, J. D. (2007). Emotional intelligence and emotional creativity. Journal of Personality, 75, 199-235.

James, W. (1961). Varieties of religious experience. New York: Collier Books. (Original work published 1902)

Kucich, G. (2001). Keats and English poetry. In S. J. Wolfson (Ed.), The Cambridge companion to Keats (pp. 186-202). Cambridge, England: Cambridge University.

Lambie, J., \& Marcel, A. (2002). Consciousness and emotion experience: A theoretical framework. Psychological Review, 109, 219-259.

Lane, R. D., Fink, G. R., Chau, P. M. L., \& Dolan, R. J. (1997). Neural activation during selective attention to subjective emotional responses. NeuroReport, 8 , 3969-3972.

Long, C. R., Seburn, M., Averill, J. R., \& More, T. A. (2003). Solitude experiences: Varieties, settings, and individual differences. Personality and Social Psychology Bulletin, 29, 578-583.

Magai, C., \& Haviland-Jones, J. (2002). The hidden genius of emotion: Life span transformations of personality. New York: Cambridge University Press.

Mellor, A. K. (2001). Keats and the complexities of gender. In S. J. Wolfson (Ed.), The Cambridge companion to Keats (pp. 214-229). Cambridge, England: Cambridge University.

Nussbaum, M. C. (1994). The therapy of desire: Theory and practice in Hellenistic ethics. Princeton, NJ: Princeton University Press.

Oatley, K. (1999). Fiction as cognitive and emotional simulation. Review of General Psychology, 3, 101-117.

Owen, S. (1992). Readings in Chinese literary thought. Cambridge, MA: Harvard University.

Rimé, B., Finkenauer, C., Luminet, O., Zech, E., \& Philippot, P. (1998). Social sharing of emotion: New evidence and new questions. In W. Stroebe and M. Hewstone (Eds.), European Review of Social Psychology (Vol. 9, pp. 145189). Chichester, England: Wiley.

Sheen, F. J. (1949). Introduction. In The Confessions of Saint Augustine (E. B. Pusey, Trans.) (pp. vii-xiv). New York: Random House.

Singelis, T. M., Triandis, H. C., Bhawuk, D. P. S., \& Gelfand, M. J. (1995). Horizontal and vertical dimensions of collectivism: A theoretical and measurement refinement. Cross-Cultural Research, 29, 240-275. 
Smith, J., \& Smith, L. (2005). Interview with artist Zhenmin Ji. Bulletin of Psychology and the Arts, 5, 5-10.

Sternberg, R. J., \& Lubart, T. I. (1991). An investment theory of creativity and its development. Human Development, 34, 1-31.

Stillinger, J. (2001). The "story" of Keats. In S. J. Wolfson (Ed.), The Cambridge companion to Keats (pp. 246-260). Cambridge, England: Cambridge University.

Sundararajan, L. (1998). Reveries of well-being in the Shih-p'in: From psychology to ontology. In A-T. Tymieniecka (Ed.), Analecta Husserliana, (Vol. LVI, pp. 57-70). Norwell, MA: Kluwer.

Sundararajan, L. (2001). Alexithymia and the reflexive self: Implications of congruence theory for treatment of the emotionally impaired. The Humanistic Psychologist, 29, 223-248.

Sundararajan, L. (2002a). The veil and veracity of passion in Chinese poetics. Consciousness and Emotion, 3, 197-228.

Sundararajan, L. (2002b). Religious awe: Potential contributions of negative theology to psychology, "positive" or otherwise. Journal of Theoretical and Philosophical Psychology, 22(2), 174-197.

Sundararajan, L. (2002c). Humanistic psychotherapy and the scientist-practitioner debate: An "embodied" perspective. Joumal of Humanistic Psychology, 42, $34-47$.

Sundararajan, L. (2004a). Twenty-four poetic moods: Poetry and personality in Chinese aesthetics. Creativity Research Joumal, 16, 201-214.

Sundararajan, L. (2004b). Ssu-k'ung T'u's vision of ultimate reality: A quantum mechanical interpretation. Ultimate Reality and Meaning, 27, 254-264.

Sundararajan, L. (2005). Happiness donut: A Confucian critique of positive psychology. Journal of Theoretical and Philosophical Psychology, 25, 35-60.

Sundararajan, L. (in press). Kong (Emptiness): A Chinese Buddhist emotion and it's therapeutic implications. In J. D. Pappas, W. Smythe, \& A. Baydala (Eds.), Cultural healing and belief systems. Calgary, AB, Canada: Detselig Enterprises.

Sundararajan, L., \& Schubert, L. K. (2005). Verbal expressions of self and emotions: A taxonomy with implications for alexithymia and related disorders. In R. D. Ellis \& N. Newton (Eds.), Consciousness 8 emotion: Agency, conscious choice, and selective perception (pp. 243-284). Amsterdam: John Benjamins.

Triandis, H. C. (1995). Individualism and collectivism. Boulder, CO: Westview Press.

Turner, M. (1996). The literary mind/The origins of thought and language. Oxford: Oxford University.

Vygotsky, L. S. (1978). Mind in society: The development of higher psychological processes. Cambridge, MA: Harvard University Press.

Watson, B. (1964). Chuang Tzu/Basic writings. New York: Columbia University Press.

Whitehead, A. N. (1933). Adventures of ideas. New York: Mentor Books. 
Wordsworth, W. (1952). Preface to second edition of lyrical ballads. In B. Ghiselin (Ed.), The creative process (pp. 83-84). Berkeley: University of California Press. (Original work published 1805)

Yu, P. R. (1978). Ssu-k'ung T'u's Shih-p'in: poetic theory in poetic form. In Ronald C. Miao (Ed.), Chinese poetry and poetics (Vol. 1, pp. 81-103). San Francisco: Chinese Materials Center.

Zajonc, R. B. (1998). Emotions. In D. T. Gilbert, S. T. Fiske, \& G. Lindzey, Handbook of social psychology (Vol. 1, pp. 591-632). Boston, MA: McGraw-Hill. 